\title{
Shear velocity-based uncertainty quantification for rock joint shear strength
}

\author{
${\text { Gaurav } \text { Tiwari }^{1} \cdot \text { Gali Madhavi Latha }}^{2}$
}

Received: 24 May 2018 / Accepted: 28 February 2019/Published online: 14 March 2019

(C) Springer-Verlag GmbH Germany, part of Springer Nature 2019

\begin{abstract}
The shear strength of rock joints is an important property required in order to analyze the stability of rock slopes and tunnels. However, estimation of the shear strength of rock joints for in situ conditions is a complex task due to various influencing factors present in the field. Among these factors, the shear velocity or the shear displacement rate along the rock joints are important parameters which are relatively less studied since their effect is considered to be of second order compared to other factors. However, some recent studies in the literature suggest that shear velocity has a significant influence on the shear strength of rock joints, and hence the shear strength of joints estimated at low shear velocities in laboratories cannot be used under in situ conditions where the possibility of higher shear velocities exist due to the presence of different factors, such as blasting, excavation, and thermal and seismic loads. In this paper, we have addressed these issues in three steps. In the first step, an experimental study on jointed rock specimens is presented to investigate the influence of the displacement rate on the shear strength of rock joints. In the second step, a probabilistic method is developed based on the experimental results and the compiled data from the literature to estimate the in situ shear strength of joints under higher displacement rate conditions, i.e., blasting, excavation, and seismic loads from laboratory-estimated shear strength at the International Society for Rock Mechanics suggested low displacement rates. In the third step, a case study of a Himalayan rock tunnel was used to demonstrate the described approach. It was observed that the shear strength of discontinuities reduced with ncreasing shear velocity and that the rate dependency was higher for low-density rocks and under high confining stress. Further, a considerable effect was observed on the probability of failure of the rock tunnel when the effect of shear velocity was considered in the stability analysis.
\end{abstract}

Keywords Rock discontinuity $\cdot$ Shear strength $\cdot$ Systematic uncertainty $\cdot$ Displacement rate $\cdot$ Uncertainty analysis

\section{Introduction}

The shear strength of rock joints is an important property which is required when estimating the stability of various rock structures, especially when the possibility of structurally controlled failure exists. The shear strength of rock joints is generally determined using laboratory testing on rock joint samples collected from the field. However, it is inappropriate to

Gaurav Tiwari

gauravt@iitk.ac.in

Gali Madhavi Latha

madhavi@iisc.ac.in

1 Department of Civil Engineering, IIT, Kanpur, India

2 Department of Civil Engineering, Indian Institute of Science, Bangalore, India use this laboratory-estimated shear strength of rock joints determined under standard conditions for the stability analysis of rock structures in the field. This is because of the presence of various discrepancies in the in situ and laboratory conditions, such as moisture, temperature, scale or shear velocity, and hence there could be significant differences between the laboratory-estimated and in situ values of the shear strength of the rock joints. Among these discrepancies, the shear velocity is an important factor since there is a high possibility of differences between its laboratory and in situ values. The shear strength of rock joints in the laboratory is estimated by applying a shear velocity in the range of $0.02-0.5 \mathrm{~mm} / \mathrm{min}$ along the rock joints as suggested by the International Society for Rock Mechanics (ISRM). However, this value of shear velocity is often exceeded in the field in the presence of various triggering factors, such as blasting, excavation, thermal loads in nuclear storage, and seismic forces. Hence, it is not appropriate to directly use the laboratory-estimated shear 
strength value for the stability analysis of rock structures in the field. There is no method currently available in the literature to estimate the in situ shear strength of rock joints at high-shear velocity from laboratory-estimated values determined at lowshear velocities. This could be due to the limited available studies present in the literature regarding rate-dependent strength behaviour of rock joints, and, further, most of these studies have reported contradictory results.

Studies have been conducted in the past by some researchers to investigate the rate-dependent strength behaviour of rock joints. Most of these studies concluded that shear velocity along the rock joints significantly affects their shear strength. Studies to investigate the rate-dependent strength behaviour of rock joints began in the late 1960s and early 1970s. Byerlee and Brace (1968) investigated the effect of different parameters on the shear behaviour of rock joints and concluded that the effect of strain rate was limited as compared to confining stress and rock types. Dieterich $(1972,1978)$ performed direct shear tests on four types of rock interfaces, i.e., sandstone, greywacke, red granite and quartzite, and concluded that the frictional strength of the rock joint increasedg with the time of static contact. Crawford and Curran (1981), and Curran and Leong (1983) investigated the effect of the displacement rate on the shear behaviour of rock joints of different rocks. In general, with increasing shear velocity, the shear resistance of the rock joints reduced for harder rocks while it increased for softer rocks. Scholz and Engelder (1976) and Wang and Scholz (1994) also observed the rate-dependency of the strength behaviour of rock joints of synthetic sapphire, westerly granite, solenhofen limestone and twin sisters dunite. It was observed that the strength along the rock joint reduced with increasing shear velocity due to creep at asperity contacts. In contrast to this, Schneider (1977) and Lajtai (1991) observed that, at the same normal stress, the frictional resistance of rock joints is higher at higher shear velocity. In recent studies, artificial rock joints are generally used to study the rate-dependent strength behaviour of rock joints. Plaster of Paris is used to model the rock joints of soft rocks (Atapour and Moosavi 2013; Atapour and Moosavi 2014; Mirzaghorbanali et al. 2014; Tang and Wong 2016; Wang et al. 2016) and concrete/mortar is used to model rock joints of hard rocks (Jafari et al. 2004; Atapour and Moosavi 2013; Atapour and Moosavi 2014). From these studies on artificial rock joints, it has been concluded that, with increasing shear velocity, the shear resistance of the rock joints increases for harder rocks while it reduces for softer rocks. These results observed for artificial rock materials contradicted the results obtained by previous researchers (Crawford and Curran 1981; Curran and Leong 1983).

It can be observed from these studies that shear velocity can affect the shear strength of rock joints in two ways: velocityweakening, i.e., the shear strength of rock joints reduces with the increasing shear velocity, or velocity-hardening, i.e., the shear strength of rock joints increases with increasing shear velocity. However, all of these studies show that the shear velocity along rock joints considerably affects the shear strength of the rock joints. Hence, the laboratory-estimated shear strength of rock joints could be significantly different from its in situ value due to possible difference in the shear velocities under laboratory and field conditions. Hence, using laboratory-estimated shear strength of rock joints directly can underestimate or overestimate the stability of rock structures.

This study aims to counter these limitations of the previous studies. The major aims of this study are (1) to investigate the rate-dependent strength behaviour of rock joints for different rock densities and to understand the governing mechanisms, and (2b) to develop a method which can be used to estimate the in itu shear strength of rock joints at higher-shear velocity from the laboratory-estimated shear strength at low-shear velocity. To achieve these aims, this detailed study has been carried out in three steps. In the first step, details regarding laboratory triaxial tests on jointed rocks are presented. This experimental study has been carried out to assess the effect of displacement rate on the shear strength of rock discontinuities for different types of rocks and under different confining stresses. In the second step, after establishing the ratedependency in rock joint strength, an analytical method based on a probabilistic approach is proposed to estimate the shear strength of discontinuities at high displacement rates for field conditions from laboratory-estimated shear strength of discontinuities at low displacement rates. In the third and final step, a stability analysis of a large Himalayan rock tunnel is carried out to demonstrate the proposed method and to estimate the effect of displacement rate on the stability of the tunnel. Figure 1 shows the general layout of the paper and the sequence of the steps in which this study has been carried out.

\section{Experimental study}

In the first step of this study, an experimental study was undertaken to investigate the effect of shear velocity on the shear strength of rock discontinuities of rocks with different densities and under different confining stresses. It has been carried to investigate the extent of the influence of the shear velocity on the shear strength of discontinuities under different conditions and further to produce the data which are required in the next section for the analytical model development. This section presents the details of the methodology and a discussion of the results of the experimental study.

\section{Sample preparation}

For the current study, Plaster of Paris (POP) was selected as the model material to prepare the rock samples since POP can be molded into any shape when mixed with water, and further 
Fig. 1 General layout of the paper

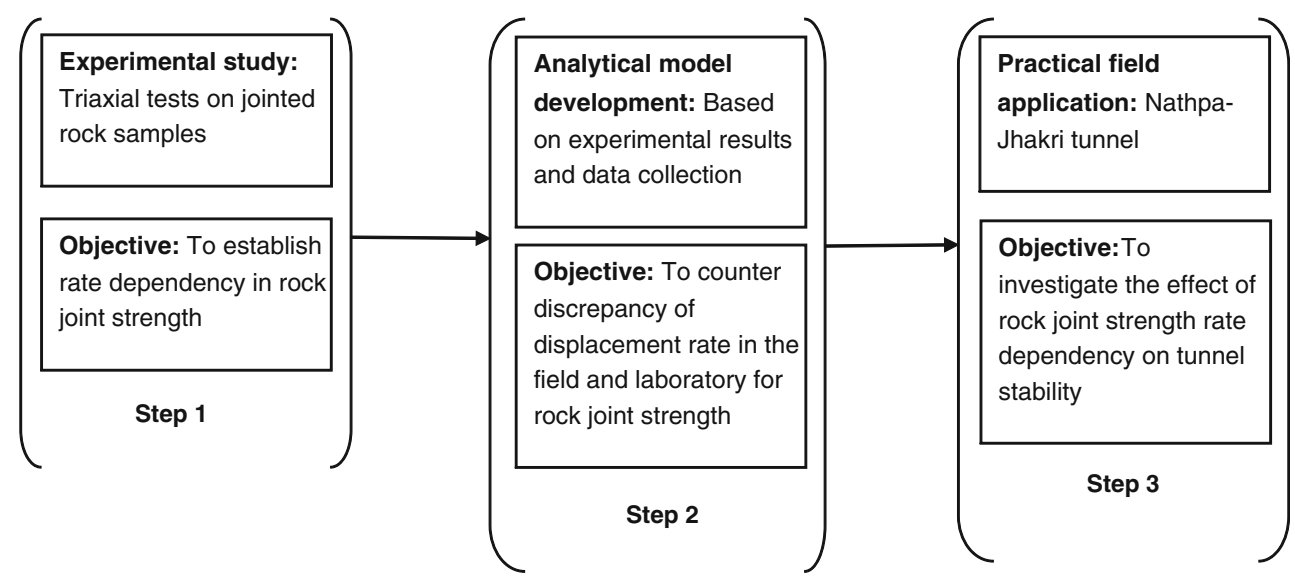

this material represents an array of sedimentary rocks of relatively low porosity (Indraratna 1990; Jafari et al. 2004; Indraratna et al. 2008). Cylindrical samples of jointed rock of $70 \mathrm{~mm}$ diameter and $140 \mathrm{~mm}$ height were prepared with the joint inclined at $60^{\circ}$ to the horizontal. Joint inclination was kept as $60^{\circ}$ to the horizontal to ensure the failure of the specimen through sliding along the joint, instead of the shearing of intact rock material(Ramamurthy 2010). A silicon rubber mould was used to replicate the similar roughness profile along the joint for all the jointed rock samples. The joint roughness coefficient of the joint was estimated to be in the range of 6-8 (Barton and Choubey 1977). The procedure adopted for preparing the jointed rock specimens is explained in Fig. 2.

Further, to investigate the effect of shear velocity on the shear strength of rock joints of rocks with different densities, jointed rock samples of different densities were prepared by varying the $\mathrm{POP}$-water ratios. Table 1 shows the water-POP ratios and basic mechanical properties for the prepared rock materials of different densities. The basic properties of the rocks were estimated by carrying out uniaxial loading tests on cylindrical intact rock samples of different densities. Figure 3 shows the stress-strain curves for rocks of different densities under unconfined conditions. It can be observed from Table 1 and Fig. 3 tha,t with the reducing density of the rock (from M1 to M3), different mechanical properties of the rocks, i.e., stiffness, strength and brittleness were reduced.

\section{Experimental program}

For the current study, triaxial compression tests were carried out on jointed rock samples to determine the effect of displacement rate on the strength behaviour of the rock joints. For jointed rock specimens of each rock type, tests were conducted at three different confining stresses in the range of 200-600 kPa. For each confining stress, tests were conducted for the displacement rate range of $0.05-15 \mathrm{~mm} / \mathrm{min}$. The displacement rates for the current study were chosen in order to
Fig. 2 Sample preparation: a the mould, b prepared cylindrical samples, $\mathbf{c}$ creation of joint, $\mathbf{d}$ prepared jointed rock samples a
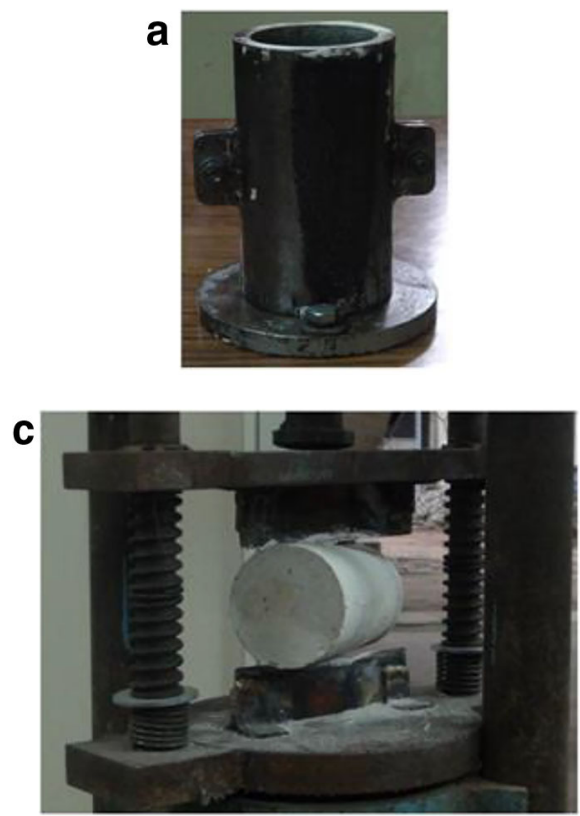

b
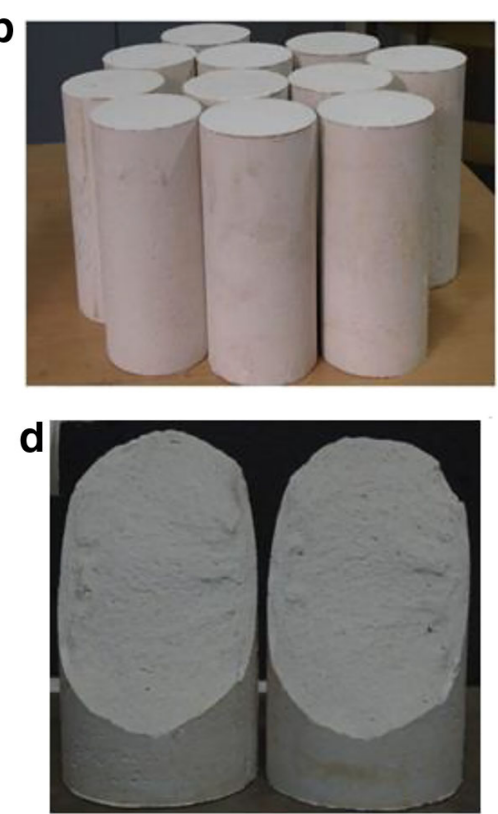
Table 1 Basic properties of intact rocks of different densities used in the present study

\begin{tabular}{llll}
\hline Property & M1 & M2 & M3 \\
\hline Plaster:water ratio & $5: 3$ & $5: 3.5$ & $5: 4$ \\
Uniaxial compressive strength (MPa) & 4.53 & 3.07 & 2.07 \\
Elastic modulus (GPa) & 0.56 & 0.46 & 0.37 \\
Modulus ratio & 124 & 150 & 181 \\
Drop modulus (MPa) & 4.08 & 1.47 & 0.80 \\
\hline
\end{tabular}

represent the displacement rates in rock joints generally encountered during the excavation of tunnels and slopes, small earthquakes and thermal loads, which are important in cases of underground nuclear waste storage (Jafari et al. 2004; Atapour and Moosavi 2014). Table 2 presents the details of parameters used in the triaxial compression tests carried out on jointed rock specimens.

\section{Results}

This section briefly presents the results and discussion of the experiments performed. Table 3 presents the effect of displacement rate on the peak deviator stress for different rocks at a confining stress of $400 \mathrm{kPa}$. Figure 4 presents the stressstrain response of jointed samples of different rocks at a confining pressure of $400 \mathrm{kPa}$. Figure 5 shows the relation between peak friction angles of the rock joint with the axial displacement rates for different rocks. It can be observed that, as the displacement rate was increasing, the deviator stress and friction angle were reducing for all the rock joints, irrespective of the rock type and confining stress. While the rate dependency in the rock joint strength exists for all rock types and confining stresses, its extent and degree were highly dependent on rock type and confining stress. It was observed that the rate dependency was higher for the rock joints of low-density rocks and at higher confining stresses.

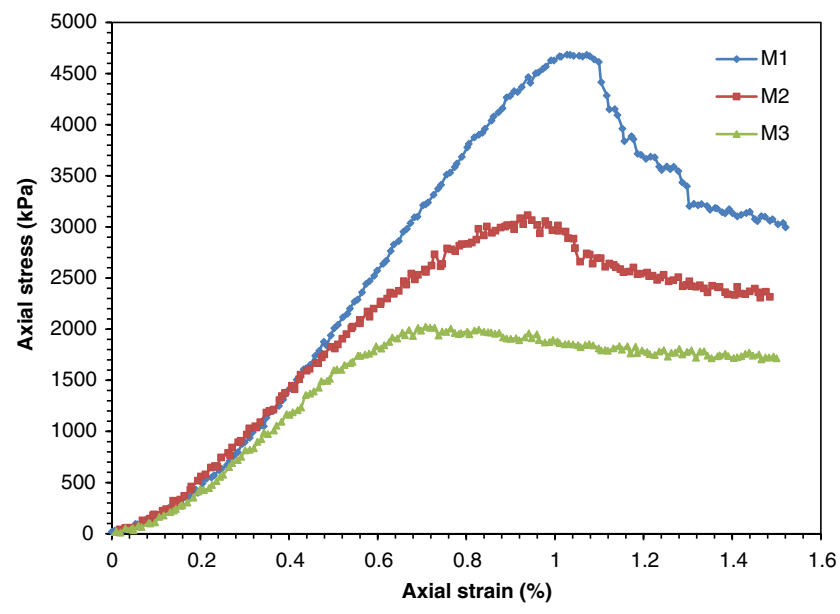

Fig. 3 Uniaxial stress-strain response of different rocks
Table 2 Details of triaxial compression tests carried out on jointed rock specimens

\begin{tabular}{lll}
\hline Rock type & Confining stresses $(\mathrm{kPa})$ & Displacement rates $(\mathrm{mm} / \mathrm{min})$ \\
\hline M1 & $200,400,600$ & $0.05,0.5,5,15$ \\
M2 & $200,400,600$ & $0.05,0.5,5,15$ \\
M3 & $200,400,600$ & $0.05,0.5,5,15$ \\
\hline
\end{tabular}

The most probable reason behind the observed results is the time-dependent deformation of the rock. The actual contact along the rock surfaces is limited to some asperity contact points which are much smaller than the large apparent contact area of the joint surfaces. When the displacement rate is small, the time of contact at these asperity contact points is higher, which results in the larger increase in the actual contact area at the asperity contact points due to higher time-dependent deformation of the rock as compared to the case when the displacement rate is high. This correlation between the rate dependency of rock joint strength with the time-dependent deformation tendency in the rock has also been studied by some earlier researchers (Swolfs 1971; Teufel 1976; Scholz and Engelder 1976; Teufel and Logan 1977, Dieterich (1978). Further, the increased rate-dependency of rock joint strength with the increasing density and confining stress can also be explained on the basis of the time-dependent deformation tendency of the tested rocks. Rate dependency in the rock joint strength was higher under those factors, i.e., low density of rocks and high confining stress which increase the tendency of the rock to undergo higher time-dependent deformation, i.e., low rock density and higher confining stress. A typical example of increasing time-dependent deformation in the rock with decreasing rock density is shown in Fig. 6 observed during indentation creep experiments on the tested rock. Further, Fig. 7 also shows the remaining undamaged area of the joint surface after shearing under different rates (enclosed by red lines). It was observed that the damaged area was decreasing with increasing axial velocity. This could be due to timedependent deformation of the rock at the asperities contacts due to which the contact area and contact points of the asperities along the surface increases for low displacement rates which cause more surface damage for low axial velocities.

\section{Estimation of in situ shear strength of rock joints at higher displacement rates from laboratory-estimated shear strength of rock joints}

After establishing the effect of displacement rate on the shear strength of rock discontinuities through the experimental study, the next step is to take this effect of displacement rate into account in the in situ shear strength 
Table 3 Effect of displacement rate on the peak deviator stress of rock joints for different rocks at a confining stress of $400 \mathrm{kPa}$

\begin{tabular}{llllll}
\hline Model material & \multicolumn{2}{l}{ Peak deviator stress (MPa) } & Decrease rate (\%) \\
\cline { 2 - 5 } & $0.05 \mathrm{~mm} / \mathrm{min}$ & $0.5 \mathrm{~mm} / \mathrm{min}$ & $5 \mathrm{~mm} / \mathrm{min}$ & $15 \mathrm{~mm} / \mathrm{min}$ \\
\hline M1 & 4.300 & 3.998 & 3.837 & 3.510 & 18.37 \\
M2 & 3.034 & 2.910 & 2.756 & 2.457 & 19.00 \\
M3 & 2.100 & 1.912 & 1.742 & 1.603 & 23.66 \\
\hline
\end{tabular}

estimation of rock joints. For this purpose, a probabilitybased method has been developed which can be used to estimate the in situ shear strength of rock discontinuities at higher displacement rates from the laboratory-estimated shear strength at low displacement rates. Development of this method was carried out on the basis of the results of the experimental study described in the previous section and the data collected from previous studies present in the literature. This section presents the brief details of the theoretical background of the developed probabilistic model and its application in the context of the present study.

\section{Theoretical details of the probabilistic model}

Let the true/in situ peak/residual friction angle of the rock joint at a higher displacement rate be represented as $\phi^{p / r}$. Let the variable $\hat{\phi}^{p / r}$ be the estimator of the true friction angle, i.e., $\phi^{p /}$ $r^{r}$ that is measured from laboratory testing at a low displacement rate suggested by ISRM (ISRM 1981). The relationship between $\phi^{p / r}$ and $\hat{\phi}^{p / r}$ can be expressed as follows (Tang et al. 1976):

$\phi^{p / r}=N_{O}^{p / r} N_{S}^{p / r} \hat{\phi}^{p / r}$,

where $N_{O}^{p / r}$ is the correction factor corresponding to the statistical uncertainty due to the limited number of tests; $N_{S}^{p / r}$ is the correction factor corresponding to the systematic uncertainty due to differences in the laboratory testing and the in situ displacement rates along the rock joint during shearing, $\hat{\phi}^{p / r}$ is the estimator of $\phi^{p / r}$ accounting for inherent variability in the shear strength. Since $\phi^{p / r}$ contains inherent randomness, $\hat{\phi}^{p / r}$ should also naturally be a random variable. Further, the correction factors $N_{O}^{p / r}$ and $N_{S}^{p / r}$ are also taken as random variables.

Using a first-order uncertainty analysis model, the mean of $\phi^{p / r}$ can be calculated as follows:

$\mu_{\phi}^{p / r}=\vec{N}_{O}^{p / r} \vec{N}_{S}^{p / r} \vec{\phi}^{p / r}$, where $\mu_{\phi}^{p / r}$ is the mean value of true peak/residual friction angle, i.e., $\phi_{p / r} ; \bar{N}_{O}^{p / r}$ is the mean of $N_{O}^{p / r}$ whose value is 1.0; $\bar{N}_{S}^{p / r}$ is the mean of $N_{S}^{p / r} ; \bar{\phi}_{p / r}$ is the mean value of $\hat{\phi}_{p / r}$.

The total coefficient of variation (cov) of $\phi^{p / r}$ can be estimated as follows:

$\Omega_{\phi_{p / r}}=\sqrt{\Delta_{O}^{2}+\Delta_{S_{p / r}}^{2}+\delta_{\phi_{p / r}}^{2}}$,

where $\Omega_{\phi_{p / r}}$ is the total $\operatorname{cov}$ of $\phi^{p / r} ; \Delta_{O}$ is the $\operatorname{cov}$ of $N_{O}^{p / r}$ accounting for statistical uncertainty; $\Delta_{S_{p / r}}$ is the cov of $N_{S}^{p / r}$ accounting for systematic uncertainty due to differences in the displacement rate during joint shear; $\delta_{\phi_{p / r}}$ is the cov of $\hat{\phi}^{p / r}$ accounting for inherent variability.

A step-by-step procedure to estimate the statistical parameters of the true value of the friction angle will now be explained. In the cases where $n$ independent values of friction angles $\left(\phi_{1}^{p / r}, \phi_{2}^{p / r}, \ldots \ldots, \phi_{n}^{p / r}\right)$ are available from the laboratory testing at low displacement rates, common methods like sample mean and variance can be used to estimate the statistical parameters:

$\bar{\phi}^{p / r}=\frac{1}{n} \sum_{i=1}^{n} \phi_{i}^{p / r}$

$s_{\phi_{p / r}}^{2}=\frac{1}{n-1} \sum_{i=1}^{n}\left(\phi_{i}^{p / r}-\bar{\phi}^{p / r}\right)^{2}$,

where $\bar{\phi}^{p / r}$ and $s_{\phi_{p / r}}^{2}$ are the sample mean and sample variance of laboratory-measured friction angles of rock joints $\left(\hat{\phi}^{p / r}\right)$. The cov of the friction angle $\delta_{\phi_{p} / r}$ can be estimated from its sample mean and variance as follows:

$\delta_{\phi_{p / r}}=\frac{s_{\phi_{p / r}}}{\bar{\phi}^{p / r}}$

Statistical uncertainty can be estimated using the following relationship:

$\Delta_{O}=\frac{\delta_{\phi_{p / r}}}{\sqrt{n}}$ 

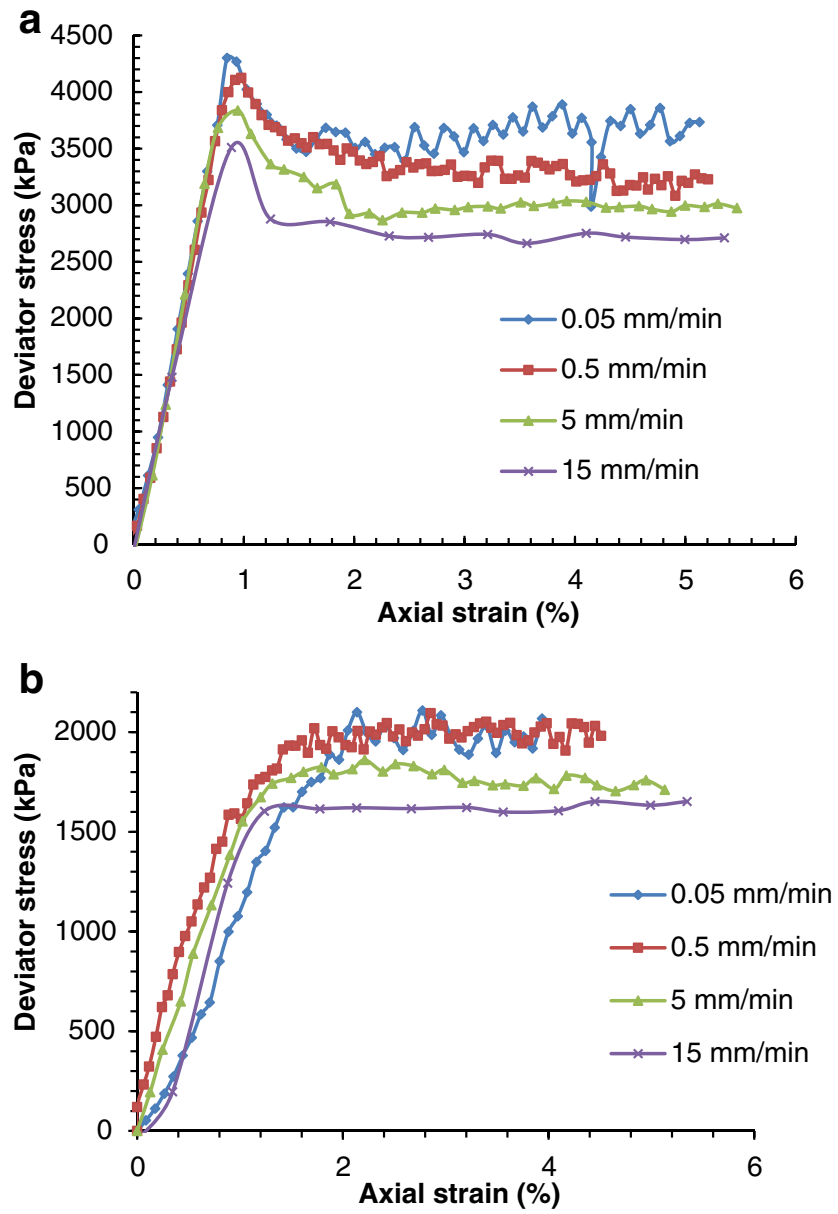

Fig. 4 Stress-strain response of different rock joints at a confining pressure of $400 \mathrm{kPa}:$ a M1, b M3

It can be observed from Eqs. 2-7 that, for the estimation of statistical parameters of the true/in-situ value of the friction angle at higher displacement rates, all the parameters can be evaluated from laboratory testing except the statistical parameters of the correction factor $N_{S}^{p / r}$, i.e. mean $\left(\bar{N}_{S}^{p / r}\right)$ and cov $\left(\Delta_{S}\right)$. Estimation of the statistical parameters for the correction factor is explained in the next section.

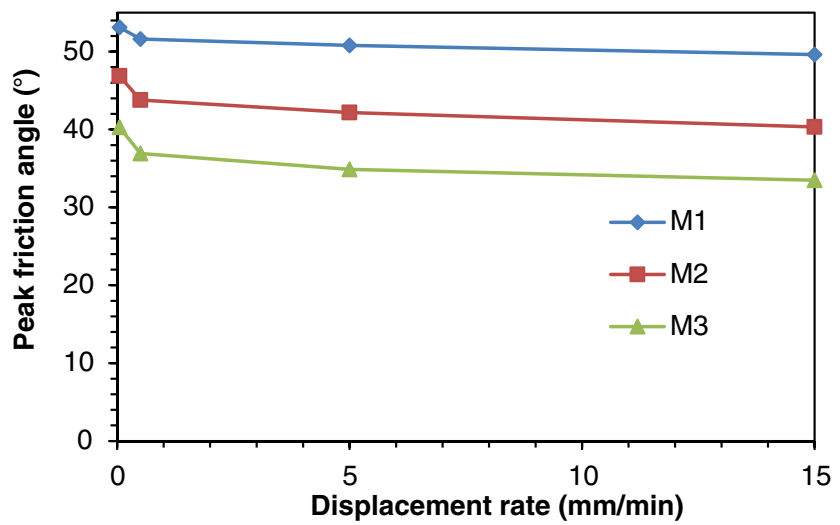

Fig. 5 Effect of displacement rate on the peak friction angle for different rock joints

\section{Estimation of the statistical parameters of the displacement rate correction factor}

For the estimation of the statistical parameters of the correction factor for the displacement rate, a comprehensive database was compiled from the literature by collecting the data from direct shear tests on rock joints and triaxial tests on jointed rock samples conducted at different displacement rates. Results from experiments carried out in the present study have also been added to the database. Table 4 shows the data compiled for the peak friction angle at different displacement rates along with the computed correction factor for the peak friction angle $\left(N_{S}^{p}\right)$. Table 5 shows the data compiled for the residual friction angle at different displacement rates along with the computed correction factor for the residual friction angle $\left(N_{S}^{r}\right)$. The relevance of the residual friction angle is more evident in the strain-softening regime of the rock joint stress-strain response, when the joint suffers higher displacement than the displacement corresponding to peak strength. Correction factors are estimated by dividing the friction angles estimated at higher displacement rates than the laboratory-suggested displacement rates by the friction angles estimated at laboratory-suggested displacement rates.

The range of displacement rate correction factors for peak and residual friction angles can be established from the data collected from the experimental results and the literature presented in Tables 4 and 5. After estimating the ranges of the correction factors, the statistical parameters of the factors can be estimated for different probability distributions of them, as shown in Table 6 . Tables 7 and 8 show the estimated range and statistical parameters of the displacement rate correction factors for peak and residual friction angles, respectively. These statistical parameters of the correction factor can be used to estimate statistical parameters of $\phi^{p / r}$ using Eqs. 2, 3 and Eqs. 4-7. There are some guidelines for using these factors which are explained in the next section.

\section{Guidelines regarding the use of the statistical parameters of the displacement rate correction factors}

Some general guidelines regarding the development and use of these correction factors are summarized as follows:

a) These correction factors can be used for all types of rock joints irrespective of the roughness, since, in recent studies (Mehrishal et al. 2016; Wang et al. 2016), the rate dependence of rock joint strength was found to have no definite relationship with joint roughness characteristics.

b) Classification is provided on the basis of the type of rate dependency in rock joints: namely, velocity-strengthening, i.e., shear strength increases with the increasing 
Fig. 6 Stages of indentation: a experimental set-up and Initial stage to final stage of indentation, b measured creep for different rocks at an indentation load of $40 \mathrm{~N}$
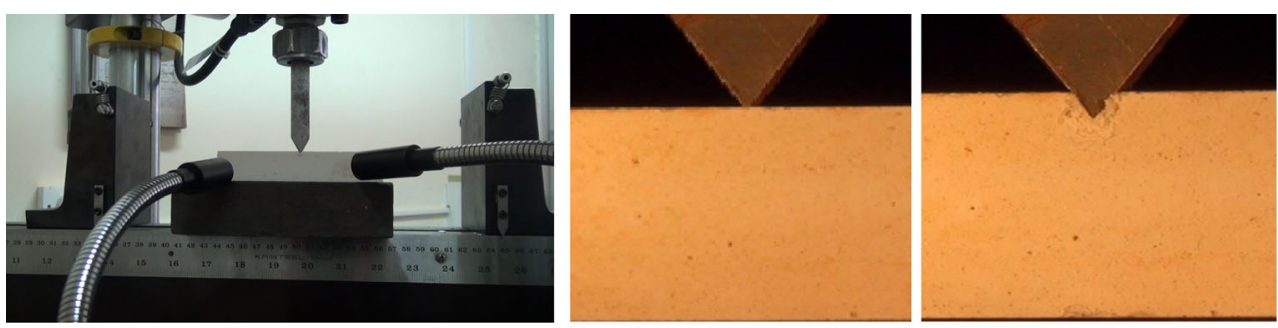

a

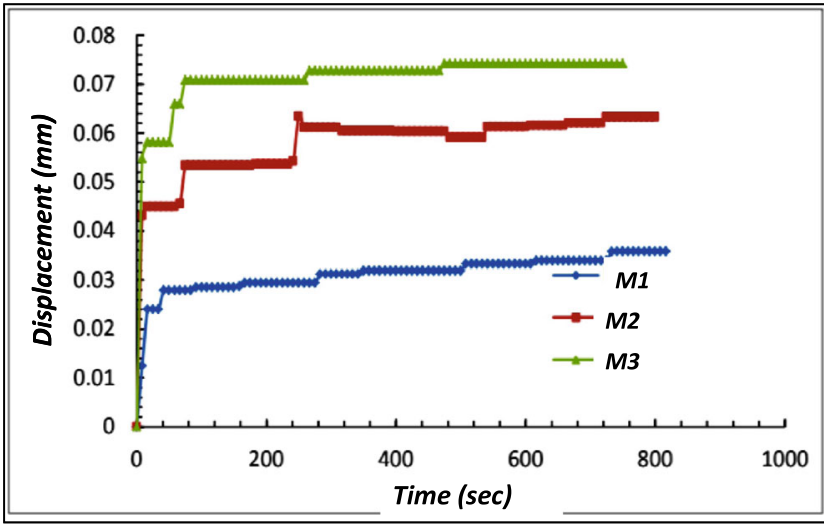

b

displacement rate, and velocity-weakening, i.e., shear strength reduces with the increasing displacement rates. The mechanism of velocity-strengthening rock joint behaviour is generally related to the similar mechanismgoverning rate dependency in intact rock uniaxial strength. The mechanism of velocity-weakening behaviour is governed by the creep of the asperities of the rock joints.

c) For the proper selection of the correction factors, it is required to classify the rock joints on the basis of their types of rate-dependent behaviour, i.e., the velocityweakening and velocity-strengthening expected during shearing along rock joints. A literature review provides general guidelines for the expected behaviour of rock joints in different rocks. As per these guidelines, Saraburi marble, opalinuston, marl, schist and granite fall under the velocity-strengthening category, while saint beat marble and sandstone fall under the velocityweakening category. However, it is suggested that at least two shear tests on rock discontinuities at different displacement rates should be conducted to obtain a rough idea regarding the expected rate-dependent behaviour of rock joints and then to select the appropriate correction factor from Tables 7 and 8 .

d) After the classification of the rocks on the basis of the expected rate-dependent behaviour of the rock joints, selection of the proper probability distribution for the correction factor is required. For the selection of the proper probability distribution for the correction factor, knowledge of site conditions and expert judgment are very important. For example, if the expected displacement rates during rock joint shearing are going to be higher, as in locations of higher seismicity, for velocity-weakening joints, the lower triangular distribution seems to be a better choice since the smaller values of the correction factors are more probable for this distribution. A similar judgment is needed for all other site conditions.

\section{Application example}

In this section, the proposed methodology explained in the previous section is demonstrated to show the effect of displacement rate on the shear strength of rock joints and hence on the stability estimate of a rock tunnel. The Nathpa Jakhri tunnel, India, has been selected as the case study for the present article due to the detailed knowledge available about the geological and geotechnical aspects of the project.

\section{Description of the rock tunnel}

The Nathpa Jhakri hydropower project in the state of Himachal Pradesh in India involved a major opening of a powerhouse cavern of dimensions $216 \mathrm{~m} \times 20 \mathrm{~m} \times$ $49 \mathrm{~m}$ (length $\times$ width $\times$ height) at a depth of $262.5 \mathrm{~m}$ 
Fig. 7 Undamaged area of the joint surface sheared under different rates (enclosed by red lines): a original profile before shearing, $\mathbf{b}$ area of remaining undamaged area of the joint surface for an axial velocity of $0.05 \mathrm{~mm} / \mathrm{min}, \mathbf{c}$ area of remaining undamaged area of the joint surface for an axial velocity of $15 \mathrm{~mm} / \mathrm{min}$ a
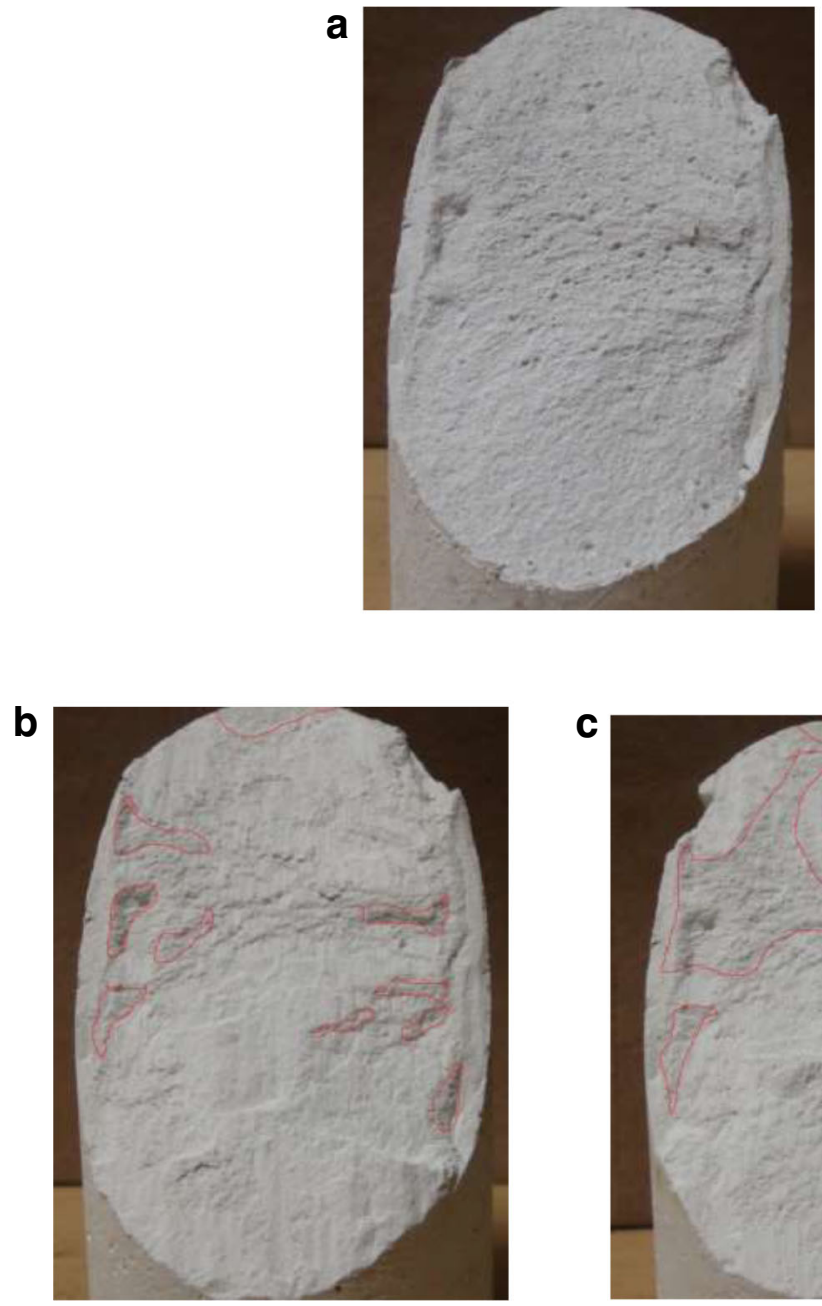

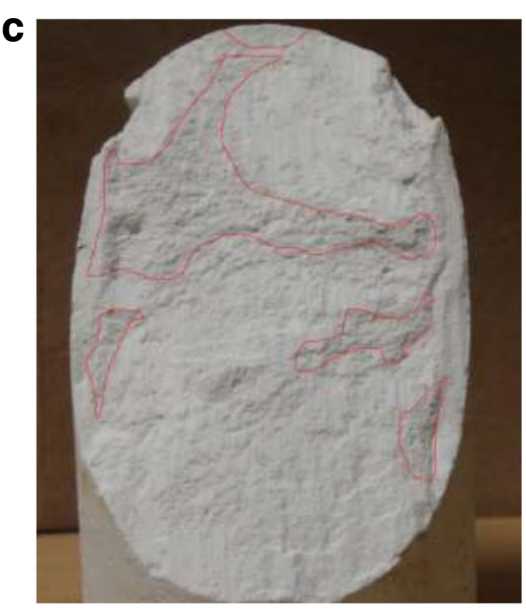

below ground level. The opening is located on the left bank at about $500 \mathrm{~m}$ from the River Sutlej with the longitudinal axis of the openings oriented in the N-S direction. The measured in situ stresses are 4.73 and $6.34 \mathrm{MPa}$ in the $\mathrm{E}-\mathrm{W}$ and $\mathrm{N}-\mathrm{S}$ directions, respectively, and $5.89 \mathrm{MPa}$ in the vertical direction. The major lithology of the site consists of quartz mica schist. It was observed that generally three joint sets along with some random joints were present at the site forming wedgeshaped blocks. Joints present at the site were generally undulating with smooth to rough surfaces having staining on the surfaces of clean joints. When excavation was carried out there was a possibility of the wedges falling from the roof or sidewalls.

\section{Quantification of uncertainties in the properties of rock discontinuities}

For the present study, an uncertainty is considered in the joint set orientations and shear strength parameters of the discontinuities. Table 9 shows the mean value and Fisher's constant for the major joint set orientations. Statistical parameters for the shear strength of discontinuities are estimated for different cases to provide a quantitative estimate of the effect of different types of uncertainties on the total uncertainty of the shear strength parameters of the discontinuities. Because of the several ambiguities on the existence of cohesion for the rock joints, only the friction angle is considered as a dominant component contributing to the shear strength of the discontinuities (Duzgun et al. 2002). Three cases of uncertainty analysis were carried out. For the first case, only inherent uncertainty was included. For the second case, statistical uncertainty was included along with inherent uncertainty. For the third case, systematic uncertainty due to displacement rate was included along with inherent and statistical uncertainties. As mentioned earlier, the friction angle is considered as the major component of the shear strength of discontinuities, while the cohesion of the rock joints is neglected in the present study. A total of 42 direct shear tests were conducted on the natural rock joints, from which 14 different values of friction angles were obtained. The estimated mean and standard deviation in the friction angle from the laboratory test data were $35.20^{\circ}$ and 
Table 4 Data used for the estimation of the correction factors for the peak friction angle

\begin{tabular}{|c|c|c|c|c|c|c|}
\hline Rock type & $\mathrm{DR}^{\mathrm{lab}}(\mathrm{mm} / \mathrm{min})$ & $\phi_{p}^{l a b}\left(^{\circ}\right)$ & $\mathrm{DR}^{\text {field }}(\mathrm{mm} / \mathrm{min})$ & $\phi_{p}^{\text {field }}\left({ }^{\circ}\right)$ & $N_{S}^{p}$ & Ref \\
\hline Opalinuston & 0.1 & 19.30 & 10 & 20.11 & 1.04 & Schneider (1977) \\
\hline Marble & 0.3 & 41.34 & 1.2 & 33.94 & 0.82 & Hoang et al. (2010) \\
\hline Synthetic & 0.5 & 41 & 50 & 45.72 & 1.12 & Li et al. (2012) \\
\hline Granite & 0.15 & 33.18 & 0.69 & 34 & 1.02 & Kleepmek (2014) \\
\hline Sandstone & 0.15 & 35.93 & 0.69 & 41.32 & 1.15 & Kleepmek (2014) \\
\hline Marl & 0.15 & 34.13 & 0.69 & 36.73 & 1.08 & Kleepmek (2014) \\
\hline Granite & 0.07 & 55.59 & 0.7 & 56.48 & 1.02 & Kleepmek (2014) \\
\hline Sandstone & 0.07 & 54.45 & 0.7 & 55.18 & 1.01 & Kleepmek (2014) \\
\hline Marl & 0.07 & 53.39 & 0.7 & 54.61 & 1.02 & Kleepmek (2014) \\
\hline Saraburi marble & 0.06 & 48 & 6 & 52.91 & 1.10 & Meemun (2014) \\
\hline Synthetic & 0.3 & 39.2 & 30 & 27 & 0.69 & Atapour and Moosavi (2014) \\
\hline Synthetic & 0.3 & 30.5 & 30 & 34.2 & 1.12 & Atapour and Moosavi (2014) \\
\hline Onyx marble & 0.1 & 5.53 & 50 & 9.54 & 1.72 & Mehrishal et al. (2016) \\
\hline Travertine & 0.1 & 8.07 & 50 & 7.33 & 0.91 & Mehrishal et al. (2016) \\
\hline Onyx marble & 0.1 & 37.22 & 50 & 42.46 & 1.14 & Mehrishal et al. (2016) \\
\hline Travertine & 0.1 & 41.71 & 50 & 42.04 & 1.01 & Mehrishal et al. (2016) \\
\hline Synthetic & 0.5 & 51.62 & 15 & 49.62 & 0.96 & Present study \\
\hline Synthetic & 0.5 & 43.78 & 15 & 40.32 & 0.92 & Present study \\
\hline Synthetic & 0.5 & 37 & 15 & 33.5 & 0.90 & Present study \\
\hline
\end{tabular}

$2.006^{\circ}$, respectively, estimated using Eqs. 4 and 5. Inherent variability in terms of the cov can be estimated using Eq. 6 as:

$\delta_{\phi_{\mathrm{p} / \mathrm{r}}}=\frac{2.006^{\circ}}{35.20^{\circ}}=0.057$
Statistical uncertainty in the friction angle due to the limited number of laboratory tests can be estimated using Eq. 7 as:

$\Delta_{\mathrm{O}}=\frac{0.057}{\sqrt{14}}=0.015$

Table 5 Data used for the estimation of correction factors for the residual friction angle

\begin{tabular}{|c|c|c|c|c|c|c|}
\hline Rock type & $\mathrm{DR}^{\mathrm{lab}}(\mathrm{mm} / \mathrm{min})$ & $\phi_{r}^{l a b} \quad\left(^{\circ}\right)$ & $\mathrm{DR}^{\text {field }}(\mathrm{mm} / \mathrm{min})$ & $\phi_{r}^{\text {field }}\left({ }^{\circ}\right)$ & $N_{S}^{r}$ & Reference \\
\hline Marble & 0.3 & 32.61 & 1.2 & 30.11 & 0.92 & Hoang et al. (2010) \\
\hline Synthetic & 0.5 & 23 & 50 & 41 & 1.78 & Li et al. (2012) \\
\hline Granite & 0.15 & 33.18 & 0.69 & 34 & 1.02 & Kleepmek (2014) \\
\hline Sandstone & 0.15 & 35.93 & 0.69 & 41.32 & 1.15 & Kleepmek (2014) \\
\hline Marl & 0.15 & 34.13 & 0.69 & 36.73 & 1.08 & Kleepmek (2014) \\
\hline Granite & 0.07 & 50.63 & 0.69 & 51.84 & 1.02 & Kleepmek (2014) \\
\hline Sandstone & 0.07 & 52.19 & 0.69 & 53.49 & 1.02 & Kleepmek (2014) \\
\hline Marl & 0.07 & 52.38 & 0.69 & 53.57 & 1.02 & Kleepmek (2014) \\
\hline Saraburi mMarble & 0.06 & 36.21 & 6 & 42.42 & 1.17 & Meemun (2014) \\
\hline Synthetic & 0.3 & 39.2 & 30 & 27 & 0.69 & Atapour and Moosavi (2014) \\
\hline Synthetic & 0.3 & 30.5 & 30 & 34.2 & 1.12 & Atapour and Moosavi (2014) \\
\hline Onyx marble & 0.1 & 4.53 & 50 & 8.05 & 1.77 & Mehrishal et al. (2016) \\
\hline Travertine & 0.1 & 4.66 & 50 & 6.55 & 1.40 & Mehrishal et al. (2016) \\
\hline Onyx marble & 0.1 & 35.90 & 50 & 41.63 & 1.16 & Mehrishal et al. (2016) \\
\hline Travertine & 0.1 & 40 & 50 & 40.01 & 1.02 & Mehrishal et al. (2016) \\
\hline Synthetic & 0.5 & 49.81 & 15 & 47.22 & 0.95 & Present study \\
\hline
\end{tabular}


Table 6 Estimation of statistical parameters corresponding to different distributions (Ang and Tang 1984)

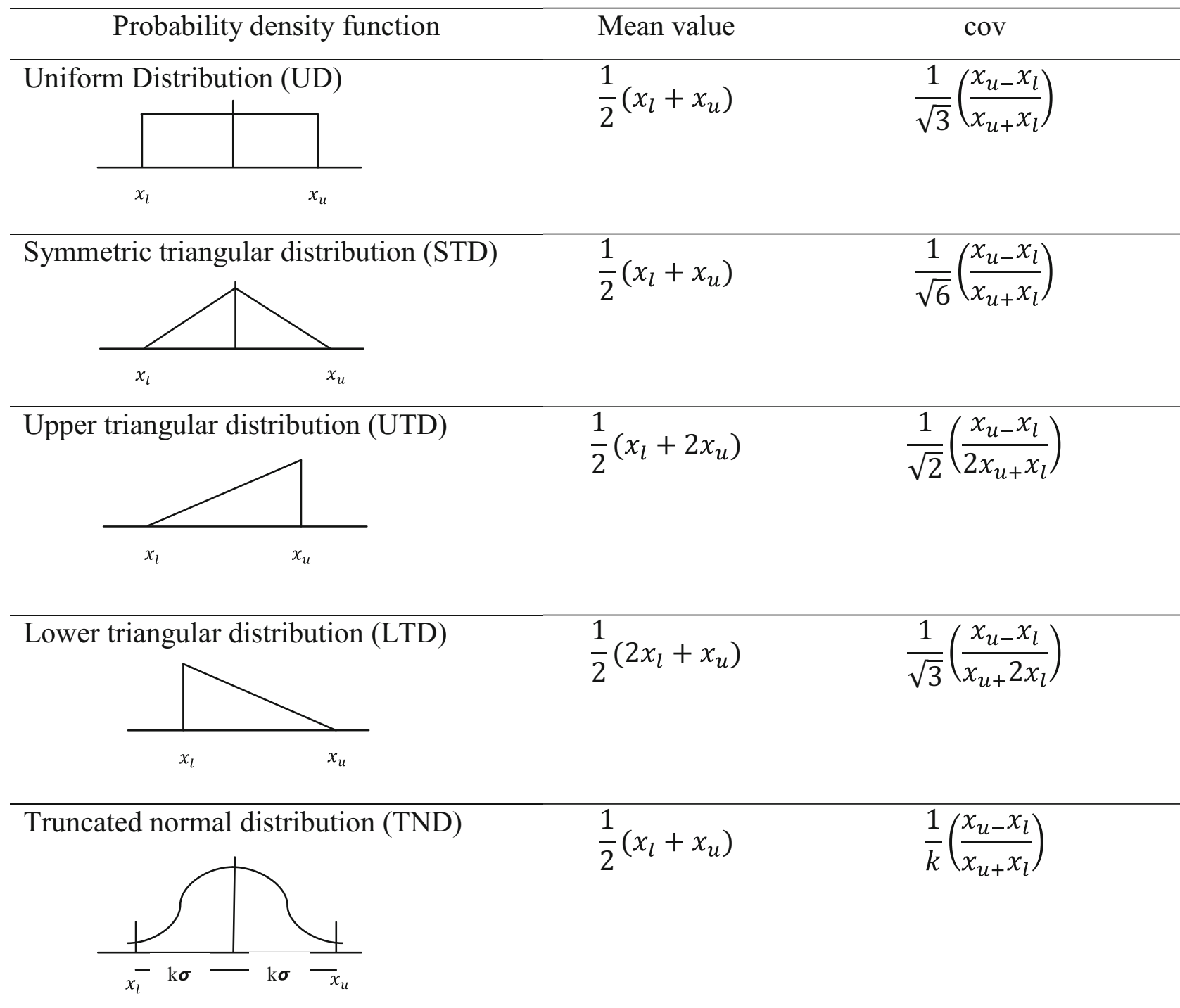

Table 7 Range and statistical parameters of correction factors for the peak friction angle

\begin{tabular}{|c|c|c|c|c|}
\hline Rock type & Estimated range of correction factor $N_{S}^{p}$ & Assumed distribution (refer to Table 1) & $\bar{N}_{S}^{p}$ & $\Delta_{S_{p}}$ \\
\hline \multirow[t]{5}{*}{ Velocity-strengthening } & \multirow[t]{5}{*}{$1.01-1.72$} & UD & 1.365 & 0.150 \\
\hline & & STD & 1.365 & 0.106 \\
\hline & & UTD & 1.483 & 0.112 \\
\hline & & LTD & 1.246 & 0.134 \\
\hline & & TND & 1.365 & $0.130^{\mathrm{a}}$ \\
\hline \multirow[t]{5}{*}{ Velocity-weakening } & \multirow[t]{5}{*}{$0.69-0.96$} & UD & 0.825 & 0.094 \\
\hline & & STD & 0.825 & 0.067 \\
\hline & & UTD & 0.870 & 0.073 \\
\hline & & LTD & 0.780 & 0.081 \\
\hline & & TND & 0.825 & $0.082^{\mathrm{a}}$ \\
\hline
\end{tabular}

LTD Lower triangular distribution, STD symmetric triangular distribution, TND truncated normal distribution, UD uniform distribution, UTD upper triangular distribution

${ }^{\mathrm{a}}$ For $\mathrm{k}=2$ as shown in Table 1 
Table 8 Range and statistical parameters of correction factors for residual friction angle

\begin{tabular}{|c|c|c|c|c|}
\hline Rock type & Estimated range of correction factor $N_{S}^{r}$ & Assumed distribution (refer to Table 1) & $\bar{N}_{S}^{r}$ & $\Delta_{S_{r}}$ \\
\hline \multirow[t]{5}{*}{ Velocity-strengthening } & \multirow[t]{5}{*}{$1.02-1.78$} & UD & 1.400 & 0.156 \\
\hline & & STD & 1.400 & 0.111 \\
\hline & & UTD & 1.526 & 0.117 \\
\hline & & LTD & 1.273 & 0.140 \\
\hline & & TND & 1.400 & $0.135^{\mathrm{a}}$ \\
\hline \multirow[t]{5}{*}{ Velocity-weakening } & \multirow[t]{5}{*}{$0.69-0.95$} & UD & 0.820 & 0.091 \\
\hline & & STD & 0.820 & 0.064 \\
\hline & & UTD & 0.863 & 0.071 \\
\hline & & LTD & 0.776 & 0.079 \\
\hline & & TND & 0.820 & $0.079^{\mathrm{a}}$ \\
\hline
\end{tabular}

LTD Lower triangular distribution, STD symmetric triangular distribution, TND truncated normal distribution, UD uniform distribution, UTD upper triangular distribution

${ }^{\mathrm{a}}$ For $\mathrm{k}=2$ as shown in Table 1

The next step is to evaluate the systematic uncertainty due to the displacement rate. Since the expected displacement rate-dependent behaviour of schist is velocitystrengthening, as mentioned earlier, the mean value and cov of the correction factor are 1.365 and 0.150 , respectively, by assuming uniform distribution of the correction factor, as shown in Table 7.

Table 10 shows the effect of different types of uncertainties on the corrected mean and total uncertainty of the friction angles of the joints estimated using Eqs. 2 and 3. It was observed that the effect of statistical uncertainty on the corrected mean and the total uncertainty of the friction angle is negligible for this case. The effect of statistical uncertainty can become more pronounced if the numbers of samples tested are fewer or the inherent uncertainty is high. It was observed that the effect of considering systematic uncertainty due to displacement rate on the statistical parameters of the friction angle is considerable. Since the rate-dependent behaviour of rock joints is expected to be velocity-strengthening, the mean value of the friction angle is increased while the uncertainty is increased. This exercise confirms that systematic uncertainty due to displacement rate is important to consider for the estimation of total uncertainty of the friction angle of rock joints.

Table 9 Statistical parameters of dip/dip directions of major discontinuities along the tunnel

\begin{tabular}{lllll}
\hline Discontinuity property & J1 & J2 & J3 & PDF \\
\hline Mean orientation (dip/dip direction) & $30 / 030$ & $70 / 120$ & $70 / 330$ & Fisher \\
Fisher's constant & 90 & 90 & 90 & \\
\hline
\end{tabular}

$P D F$ probability density function

\section{Probabilistic analysis of tunnel}

Since the rock joint orientation attributes and friction angles of joint sets contain uncertainties, it is more appropriate to analyze the stability of the tunnel in terms of the probability of failures instead of factors of safety. The probability of failure for the tunnel was evaluated for different analysis cases, as mentioned in Table 10, to show the effect of considering different types of uncertainties in the friction angles of joint sets on the estimated probabilities of failure. The probability of failure was evaluated by carrying out 10,000 Monte-Carlo simulations for each case. The probability of failure is defined as the ratio of the number of failed wedges (factor of safety $<1$ ) and total wedges (10,000 for this case). Wedge stability analysis for the tunnel was carried out using UNWEDGE software (Rocscience 2014).

Stability analysis of the tunnel against wedge failure was carried out for different cases, as shown in Table 11. Three locations were selected around the tunnel, as mentioned in the Table. It was observed that inclusion of systematic uncertainty due to displacement rate in the estimation of total uncertainty in the friction angle of the rock joints considerably affects the probability of failure. It can be observed that the probability of failure for Case 3 was considerably different from Cases 1 and 2 , which shows the effect of displacement rate on the

Table 10 Effect of considering different types of uncertainties on the estimated total uncertainty of the friction angle of rock joints

\begin{tabular}{llll}
\hline Case number & Considered uncertainties & $\mu_{\phi}^{p / r}$ & $\Omega_{\phi_{p / r}}$ \\
\hline Case 1 & Inherent & 35.20 & 0.057 \\
Case 2 & Inherent + statistical & 35.20 & 0.059 \\
Case 3 & Inherent + statistical + & 48.05 & 0.161 \\
& $\quad$ uncertainty due to displacement rate \\
\hline
\end{tabular}


Table 11 Effect of considering different types of uncertainties on the probability of failure for unreinforced tunnel

\begin{tabular}{llll}
\hline Case number & \multicolumn{2}{l}{ Probability of failure (\%) } \\
\cline { 2 - 4 } & Roof & Left sidewall & Right sidewall \\
\hline Case 1 & 6.7 & 7.4 & 0 \\
Case 2 & 6.7 & 7.5 & 0 \\
Case 3 & 1.4 & 1.3 & 0 \\
\hline
\end{tabular}

estimated probability of failure. The probability of failure was smaller for Case 3 as compared to Cases 1 and 2 since the expected behaviour of the rock joints is velocity-strengthening. This shows the effect of displacement rate on the estimated probability of failure of the wedges and hence it becomes important to consider this rate dependency in rock joint strength while analyzing the stability of different rock structures.

\section{Conclusions}

The following major conclusions are drawn from the experimental and probabilistic numerical analyses carried out in the present study.

The shear strength of rock joints is significantly affected by the displacement rate. For the rock joints studied in the current article, the shear strength was reduced with the increasing displacement rate. Further, decreasing rock density was enhancing this rate dependency of rock joint strength. The most probable reason behind these observations is related to the time-dependent deformation of rock at the asperity contacts.

Systematic uncertainty due to shear velocity along the rock joints during shearing is one of the important factors that govern the accurate estimation of total uncertainty in the friction angle of rock joints. Correction factors in the ranges of 0.69 1.72 and $0.69-1.78$ were suggested for peak and residual friction angles, respectively, based on the velocity-strengthening or velocity-weakening behaviour of rock type.

Stability analysis of a large jointed rock tunnel using the probabilistic approach revealed that systematic uncertainty due to displacement rate is very important to consider for joint strength estimation. The percentage difference in the probability of tunnel failure for a few cases was as high as $80 \%$ when the uncertainty in the friction angle of the rock joints due to shear velocity was included along with inherent and statistical uncertainties.

The correction factors provided in this paper are for the displacement rates corresponding to pseudo-static rates. In future, these correction factors should be further updated based on the availability of more data. Further, the correction factors for displacement rates corresponding to large earthquakes can be evaluated using similar methodology.

\section{References}

Ang AHS, Tang WH (1984) Probability concepts in engineering planning and design, vol 2. Wiley, New York, pp 333-400

Atapour H, Moosavi M (2013) Some effects of shearing velocity on the shear stress deformation behaviour of hard-soft artificial material interfaces. Geotech Geol Eng 31(5):1603-1615

Atapour H, Moosavi M (2014) The influence of shearing velocity on shear behavior of artificial joints. Rock Mech Rock Eng 47:17451761

Barton NR, Choubey V (1977) The shear strength of rock joints in theory and practice. Rock Mech 10(1-2):1-54

Byerlee JD, Brace WF (1968) Stick slip, stable sliding, and earthquakeseffect of rock type, pressure, strain rate, and stiffness. J Geophys Res 73:6031-6037

Crawford AM, Curran JH (1981) The influence of shear velocity on the frictional resistance of rock discontinuities. Int J Rock Mech Min Sci 18:505-515

Curran JH, Leong PK (1983) Influence of shear velocity on rock joint strength. Proc. of Int. Cong. Rock Mechanics, ISRM, Melbourne, 1: 235- 240

Dieterich JH (1972) Time-dependent friction in rocks. J Geophys Res 77(20):3690-3697

Dieterich JH (1978) Time-dependent friction and the mechanics of stickslip. Pure Appl Geophys 116:790-806

Duzgun HSB, Yucemen MS, Karpuz C (2002) A probabilistic model for the assessment of uncertainties in the shear strength of rock discontinuities. Int J Rock Mech Min Sci 39:743-754

Hoang TTN, Barbier MG, Sulem J, Marache A, Riss J (2010). Mechanical behavior of natural marble discontinuities. In: Proceedings of conference on Rock Mechanics in Civil and Environmental Engineering-2010, Lausanne, p 215-218

Indraratna B (1990) Development and applications of a synthetic material to simulate soft sedimentary rocks. Geotechnique 40(2):189-200

Indraratna B, Jayanathan M, Brown ET (2008) Shear strength model for over consolidated clay-infilledidealised rock joints. Geotechnique 58(1):55-65

ISRM (1981) Rock characterizition, testing and monitoring. In: Brown ET (ed) ISRM suggested methods-1981. Pergamon, New York

Jafari MK, Pellet F, Boulon M, Hosseini K (2004) Experimental study of mechanical behaviour of rock joints under cyclic loading. Rock Mech Rock Eng 37(1):3-23

Kleepmek M (2014) Effects of shear velocity on fracture shear strength of rocks under confinements. Ph.D. Thesis, 2014, Suranaree University of Technology

Lajtai EZ (1991) Time-dependent behaviour of the rock mass. Geotech Geol Eng 9:109-124

Li B, Jiang Y, Wang G (2012) Evaluation of shear velocity dependency of rock fractures by using repeated shear tests. In: Proceeding of 12th ISRM Congress, Harmonising Rock Engineering and the Environment-2012, Beijing, p 699-702

Meemun P (2014) Shear strength testing of rock fractures under constant normal load and constant normal stiffness as affected by displacement rates. Ph.D. Thesis, 2014, Suranaree University of Technology

Mehrishal S, Sharifzadeh M, Shahriar K, Song JJ (2016) An experimental study on normal stress and shear rate dependency of basic friction coefficient in dry and wet limestone joints. Rock Mech Rock Eng 49:4607-4629 
Mirzaghorbanali A, Nemcik J, Aziz N (2014) Effects of shear rate on cyclic loading shear behaviour of rock joints under constant normal stiffness conditions. Rock Mech Rock Eng 47(5):1931-1938

Ramamurthy T (2010) Engineering in rocks for slopes foundations and tunnels. Prentice-Hall of India, New Delhi

Rocscience (2014) Unwedge version 4.013, underground wedge stability analysis. In: Rocscience Inc. , Ontario, Canada

Schneider HJ (1977) The time dependence of friction of rock joints. Bull IAEG 16:235-239

Scholz CH, Engelder JT (1976) The role of asperity indentation and ploughing in rock friction-I. Asperity creep and stick-slip. Int J Rock Mech Min Sci Geomech Abstr 13:149-154

Swolfs JS (1971) Influence of pore-fluid chemistry and temperature on fracture on sandstone under confining pressure. Ph.D. Thesis, College station, Texas A\&M
Tang ZC, Wong LNY (2016) Influences of normal loading rate and shear velocity on the shear behavior of artificial rock joints. Rock Mech Rock Eng 49(6):2165-2172

Tang WH, Yucemen MS, Ang AHS (1976) Probability-based short term design of soil slopes. Can Geotech J 13:201-215

Teufel LW (1976) The measurement of contact areas and temperature during frictional sliding of Tennessee sandstone, M.Sc. thesis, Texas A\&M University

Teufel LW, Logan JM (1977) Effect of shortening rate on the real area of contact and temperatures generated during frictional sliding. Pure Appl Geophys 116:840-865

Wang W, Scholz CH (1994) Micromechanics of the velocity and normal stress dependence of rock friction. Pure Appl Geophys 143:303-315

Wang G, Zhang X, Jiang Y, Wu X, Wang S (2016) Rate-dependent mechanical behavior of rough rock joints. Int J Rock Mech Min Sci 83:231-240 